\title{
Classical conditioning of the rabbit's nictitating membrane response to a pneumatically driven vibrotactile CS
}

\author{
ANDREW NOWAK \\ The University of Iowa, Iowa City, Iowa \\ DAVID VAN DERCAR \\ University of Miami, Coral Gables, Florida \\ and \\ I. GORMEZANO \\ The University of Iowa, Iowa City, Iowa
}

\begin{abstract}
The present paper reports the development of a pneumatically driven, noiseless, vibrotactile transducer. In addition, an illustrative set of conditioning data were presented that revealed the ability of the transducer to generate an effective vibrotactile CS that was unconfounded by auditory components.
\end{abstract}

The lack of rigorous experimental control over the onset and offset of gustatory and olfactory stimulation has made visual and auditory CSs the stimuli of choice in animal conditioning research. However, conditioning research concerned with stimulus selection, associative transfer, and conditioned inhibition has stimulated the need for a CS in the only remaining sensory modality, namely, the skin sense. Yet, throughout the history of animal conditioning research, tactile stimuli have rarely been employed. Specifically, Pavlov (1927) first described the use of a vibrotactile stimulus in his research on stimulus generalization and conditioned inhibition. Subsequently, researchers have reported successful conditioning using a variety of arrangements, including a vibratory table (Sutherland \& Dworkin, 1932) and a commercial hand massager that is applied directly to the subject (Wagner, 1969; Wagner, Rudy, \& Whitlow, 1973) or to the experimental chamber (Maffione \& Kremer, 1978; Wagner, Mazur, Donegan, \& Pfautz, 1980). However, in all of these studies, the vibrotactile transducers produced auditory stimuli. As a result, it is not clear that conditioning to a purely vibrotactile stimulus has ever been demonstrated. Yet, there is a need in conditioning research to develop discrete, controllable, vibrotactile CSs to add to those already available in the visual and auditory modalities. Moreover, it would be useful to have pure vibrotactile stimulation available to employ with animal preparations for the purpose of mapping the vibrotactile sensitivity of the skin. Accordingly, the purpose of the

This research was supported by NSF Grant BNS-8419772 and NIMH Grant MH 16841. Requests for reprints should be sent to I. Gormezano, Department of Psychology, The University of Iowa, Iowa City, IA 52242. present paper is to report our development of a noiseless vibrotactile transducer system that functions as a peripheral device to an Apple II/FIRST system interfaced to a classical conditioning laboratory (Scandrett \& Gormezano, 1980). In addition, we provide an illustrative set of conditioning data for the purpose of documenting the ability of the transducer to generate a vibrotactile CS that is unconfounded by auditory stimuli.

\section{METHOD}

\section{Subjects}

The subjects were 34 naive male and female albino rabbits, each 60-80 days old and weighing about $2.0 \mathrm{~kg}$.

\section{Apparatus}

The conditioning chambers and transducers for detecting the nictitating membrane response have been described by Coleman and Gormezano (1971). Briefly, the subjects were held in conditioning chambers by Plexiglas restrainers, while movements of the nictitating membrane were recorded by a photoresistive transducer assembly located on a muzzlelike headmount fitted securely about the animal's snout. Variations in the electrical signal, generated by extension of the nictitating membrane, were digitized by our Apple II/FIRST system (Scandrett \& Gormezano, 1980) every $5 \mathrm{msec}$ with a resolution of $1 / 16 \mathrm{~mm}$ of nictitating membrane movement. The vibrotactile transducer was positioned on a Plexiglas strip that served as the platform for mounting the photoresistive transducer. To position the vibrotactile transducer on the Plexiglas strip, a 15-gauge hypodermic needle (Monoject, No. 8881-200029) was placed in a hole drilled in the Plexiglas strip, and the hub of the needle was fastened in place with epoxy. The length of the needle was cut so that only the hub remained. The vibrotactile transducer was fitted securely into the hub and remained in position throughout the experiment.

The right-hand panel of Figure 1 depicts the component parts of the vibrotactile transducer and the left-hand panel portrays the fully assembled transducer. The core of a Plexiglas rod (a) was milled to hold the bottom halves of two 3-cc Luer-Lok syringes (Becton-Dickinson, No. 5585), cut at the 1.5-cc line. Across one syringe half (b), a finger from a latex glove (d) (American Pharmaseal Labs, No. 8857) was tightly stretched 


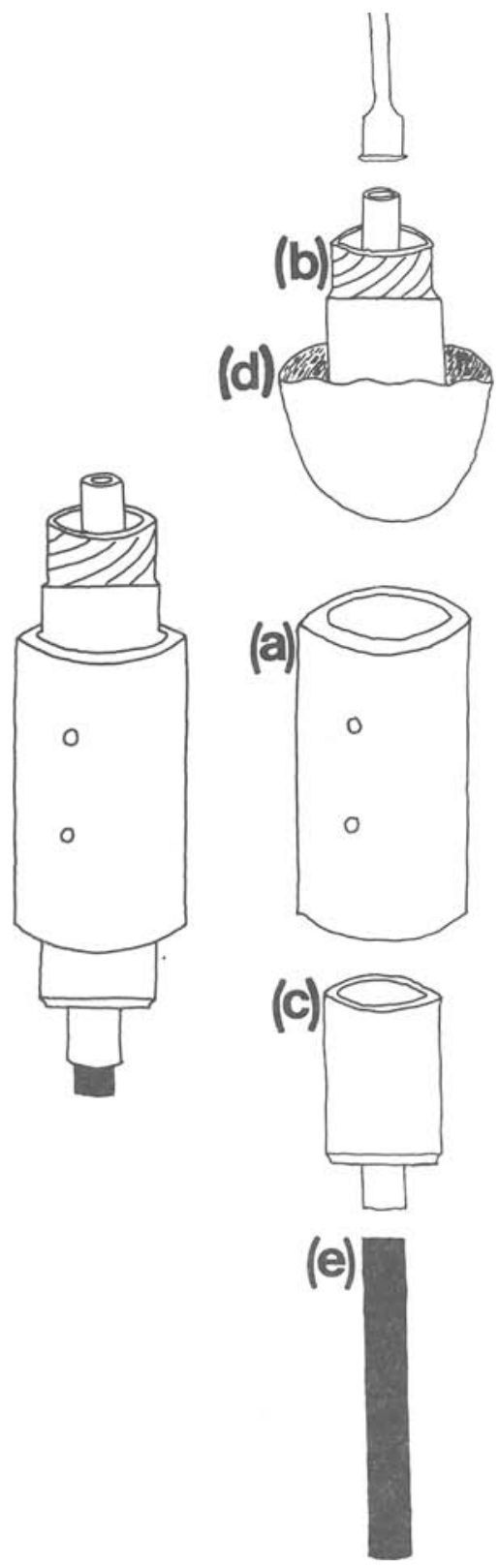

Figure 1. Schematic of the vibrotactile transducer. The right-hand panel presents the component parts of the transducer, and the lefthand panel depicts the fully assembled transducer.

and the whole piece was pushed half way into the rod and secured with a set screw. An aluminum rod (e) (Tig Tetio, D welding rod, $3 / 32$ in. diameter) was then superglued to the center of the taut glove. The second syringe half (c), with the Luer-Lok removed, was positioned over the rod and secured in place by a set screw.

A pneumatic system designed to drive the vibrotactile transducer consisted of two fuel-injection Volkswagen solenoid valves (Bosch, No. 0280150007 ) connected to a three-way fish tank valve. (The two solenoids emitted a distinctive clicking noise, so they were housed in a soundattenuated enclosure situated outside the conditioning chambers.) Compressed air (15 psi) entered from the back of the solenoids, which were alternately opened and closed, allowing air in and out of the system. This change in pressure was transmitted through polyethylene tubing
(Intramedic, I.D. $1.67 \mathrm{~mm}$, No. 7451) from the fish tank valves to the transducer, vibrating the stretched latex glove and pulsing the rod. The conditioning chambers consisted of four three-drawer sound-attenuated fireproof file cabinets. Each file cabinet had its own pneumatic system capable of stimulating each of the 3 subjects simultaneously. The four pneumatic systems received compressed air from a common tank and were electrically controlled by a 555-timer (Philips ECG, ET 1514) and relay system. Once activated, the timer emitted a pulse train that alternately opened and closed the contacts which regulated the solenoid valves. The timers were activated by the Apple II/FIRST computer system through a relay driver and relay. To set the frequency of the vibrotactile stimulus, an oscilloscope was used to manually adjust the potentiometers that controlled the 555-timer's pulse train.

The vibrotactile transducer was positioned on the Plexiglas strip so that it stimulated the top of the rabbit's head at the base of the ears. In the present experiment, the CS was a 400 -msec activation of the vibrotactile transducer at a frequency of $10 \mathrm{~Hz}$. The US was a 50-msec, $3-\mathrm{mA}, 60-\mathrm{Hz}$ shock delivered to the subject's paraorbital region through two stainless steel Autoclip sutures positioned $15 \mathrm{~mm}$ apart and $10 \mathrm{~mm}$ posterior to the dorsal canthus of the right eye. The CS-US interval was $400 \mathrm{msec}$.

\section{Procedure}

All subjects received 1 day of preparation, 1 day of adaptation, and 10 days of acquisition training. During the preparation day, a 2-mm diameter loop of 6-0 Ethilon monofilament was sutured into the right nictitating membrane, and the surrounding hair was removed. During adaptation, the two stainless steel wound clips that served as shock electrodes were implanted. The restrained subjects were then placed in the conditioning chambers for a period of time equivalent to the length of the subsequent training sessions.

The subjects were randomly assigned to one of three groups receiving paired CS-US $(n=12)$, unpaired CS/US $(n=12)$, or transducer suspended CS-US $(n=10)$ presentations. During acquisition training, Group CS-US received 10 daily sessions of 60 paired presentations of the CS and US (average ITI $=60 \mathrm{sec}$ ) and 6 CS-alone test trials presented after every 10 th paired trial. Group CS/US received 10 daily sessions consisting of explicitly unpaired presentations of 66 CS-alone and 60 USalone trials (average ITI $=30 \mathrm{sec}$ ) presented in a randomized sequence within 20 trial blocks with the restriction that no more than $3 \mathrm{CS}$-alone or US-alone trials could occur consecutively. Every 11 th CS-alone trial was designated a test trial. Finally, Group CS-US Suspended received the same schedule of stimuli as Group CS-US, except the vibrotactile transducer was suspended directly above the rabbit's head and, thus, did not make contact with the subject. A CR was defined as a $0.5-\mathrm{mm}$ extension of the nictitating membrane occurring during the 400 -msec presentation of the CS and during the equivalent time before the US in Groups CS/US and CS/US Suspended.

\section{RESULTS AND DISCUSSION}

Figure 2 presents the percentage of CRs for test and experimental trials combined for all three groups across the 10 days of acquisition training with the frequency of responding for Group CS/US partitioned into CS-alone and US-alone trials. Examination of the figure reveals that Group CS-US reached an asymptotic level of approximately $95 \%$ CRs (mean $=78 \%$ ). In contrast, responding in Group CS-US Suspended did not increase over days, remaining at levels of $1 \%-2 \%$ (mean $=1.5 \%)$ and, thus, indicating that when the vibrotactile transducer is activated, there is no detectable auditory signal. For Group CS/US, the level of responding in the 400-msec interval preceding US-alone presentations was virtually absent (mean $=1.0 \%$ ), whereas the level of responding on CSalone trials reached levels as high as $6 \%-7 \%$ (mean = 


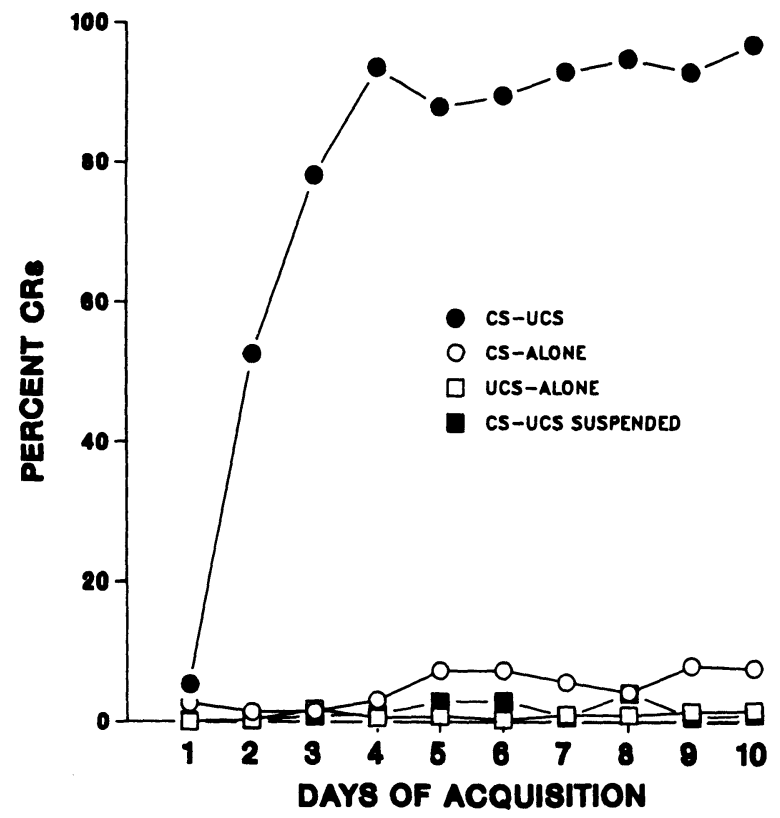

Figure 2. The mean percentage of CRs for each of the three groups with responding for Group CS/UCS presented for both CS-alone and UCS-alone trials.

4.9\%). An analysis of variance of the percent $C R$ data yielded significant effects of groups $[F(2,31)=384.77]$, days $[F(9,279)=39.66]$, and groups $\times$ days $[F(18,279)$ $=29.70$ ], indicating the ability of the vibrotactile CS to support a reliable level of conditioning. Moreover, the experiment revealed that the vibrotactile transducer produces no detectable auditory stimuli and provides a vibrotactile CS producing little or no evidence of sensiti- zation or pseudoconditioning while supporting a substantial level of NMR conditioning. Consequently, our pneumatically driven vibrotactile transducer appears to provide a tractable CS that can be used by itself or in conjunction with visual and auditory stimulation to study a range of topics in animal learning. Moreover, the presently employed vibrotactile transducer and conditioning preparation appear to provide an admirably suited system for mapping the vibrotactile sensitivity of the skin.

\section{REFERENCES}

Coleman, S. R., \& Gormezano, I. (1971). Classical conditioning of the rabbit's nictitating membrane response under symmetrical CS-US interval shifts. Journal of Comparative \& Physiological Psychology, 77, 447-455.

Maffione, J., \& Kremer, E. (1978). Excitatory conditioning to a vibrotactile stimulus using rats in a CER paradigm. The Psychological Recorder, 28, 237-243.

Pavlov, I. P. (1927). Conditioned reflexes (G. V. Anrep, Trans.). London: Oxford University Press.

SCANDRETT, J., \& GoRmEZANO, I. (1980). Microprocessor control and A/D data acquisition in classical conditioning. Behavior Research Methods \& Instrumentation, 12, 120-125.

Sutherland, G. F., \& Dworkin, S. (1932). Conditioned responses to sound and vibrations. American Journal of Physiology, 101, 89-97.

WAGNER, A. R. (1969). Stimulus selection and a "modified continuity theory." In G. H. Bowers \& J. T. Spence (Eds.), The psychology of learning and motivation (Vol. 3, pp. 1-41). New York: Academic Press.

Wagner, A. R., Mazur, J. E., Donegan, N. M., \& Pfautz, P. L. (1980). Evaluation of blocking and conditioned inhibition to a CS signaling a decrease in US intensity. Journal of Experimental Processes: Animal Behavior Processes, 6, 376-385.

WAGNer, A. R., Rudy, J. W., \& Whitlow, J. W. (1973). Rehearsal in animal conditioning. Journal of Experimental Psychology, 97, 407-426.

(Manuscript received for publication March 19, 1986.) 